\title{
Designed Mentorship, Career Development, Learning and Psychological Growth across Generations: A Study of a Mentoring Program in an International Industrial Company
}

\author{
Max Rapp Ricciardi* and Trevor Archer
}

Department of Psychology, Network for Empowerment and Well-Being, University of Gothenburg, Sweden

\begin{abstract}
The purpose of the present study was: 1) to evaluate workplace mentoring programs from the perspectives of the mentors and protégés. 2) To compare the evolution of three mentoring programs 3) to contribute to the development of the theoretical field of mentorship. Qualitative and quantitative methods were used and data was collected during a five year period at an international company. The results showed that the majority of the mentors and protégés were satisfied mainly with how the mentoring programs provided personal growth and learning. The separation between junior employees and senior employees in the mentoring programs has decreased over the year's concomitant with a strengthening of organizational culture. It was noted not only that the protégés need to be inspired, but also that mentors need inspiration as well. Resilient relationship between mentors and protégés may occur only if the gain is mutual over time. One conclusion pertains to the necessity of designing mentor programs that will contribute to the mentors' as well as the protégées' development. A model is presented that indicates how this development may be accomplished.
\end{abstract}

Keywords: Mentor; Protégé; Formal mentoring; Dyad; Psychological growth, Career development

\section{Introduction}

Increasing competition in current world markets coerces companies to become more efficient in order to survive. This development pressurizes management and to the employees to evolve their careers of expertise. The implementation of a formal workplace mentoring and coaching program has been seen as an avenue for advancement employees' competence development motivation and productivity [15], and is becoming an increasingly important aspect of companies' human resource management activities.

\section{Basics of formal mentoring}

Mentoring within a company may be defined as an intense work relationship between senior (mentor) and junior (protégé) organizational members' [6-8]. Since mentoring is a relationship driven by curiosity and reciprocal understanding for accomplishment, the mentor ought to be perceived as a professional counselor as well as a role model [9-12]. The mentor's task involves passing along certain skills and facilitating the comprehension of written and unwritten codes of organizational behavior $[7,13]$. Formal mentoring relationships are often initiated through mentoring programs where potential mentors and protégés are matched together by common interests $[3,8,14]$.

\section{The purposes of mentoring programs}

The purposes of mentoring programs are to strengthen the organization and the objectives of the mentoring program should be aligned with the goals of the organization $[1,3,15,16]$. Thus, mentoring programs established in different organizations have, according to Jacobi [17], very little in common. Nevertheless, three common features may be found: I) less experienced protégés are matched with more experienced mentors, II) a system of monitoring program activities and III) workplace recognition and rewards are awarded to successful participants [8]. The common goal of most mentoring programs is to develop the competence of the protégés with the ultimate goal of improving the competitiveness of the organization [3]. To make the formal mentoring relationship collaborative and constructive the mentoring program has to be both well-planned and well-considered $[3,18]$.

\section{Benefits of mentoring}

In a favorable situation, the mentoring program provides a constructive structure that facilitates the evolution of a positive working alliance between the mentor and the protégé in the learning process $[18,19]$. The positive consequences for an organization may include: better trained staff, development of the organizational culture, interpersonal networks $[7,19]$. The mentor's role in a mentoring program may also provide benefits for the mentor's own personal and professional improvement and an increased level of job satisfaction $[3,9,18]$. The benefit for the protégé is the support received from the mentor throughout the learning process and the procurement of greater knowledge and understanding of the organizational culture, context and its business $[9,18,19]$.

\section{Functions of mentoring}

Kram [20] conducted two detailed studies of mentoring concluding that mentors fulfill two distinct functions: a career development function and a psychosocial function. The former, career development function, includes: the mentor sponsoring the protégé in work assignments,

*Corresponding author: Max Rapp Ricciardi, Department of Psychology, Network for Empowerment and Well-Being, University of Gothenburg, Sweden, Tel: +46 31 78642 72; E-mail: max.rapp.ricciardi@psy.gu.se

Received: December 04, 2016; Accepted: December 22, 2016; Published: December 30, 2016

Citation: Ricciardi MR, Archer T (2016) Designed Mentorship, Career Development, Learning and Psychological Growth across Generations: A Study of a Mentoring Program in an International Industrial Company. Clin Exp Psychol 2: 144. doi: $10.4172 / 2471-2701.1000144$

Copyright: () 2016 Ricciardi MR, et al. This is an open-access article distributed under the terms of the Creative Commons Attribution License, which permits unrestricted use, distribution, and reproduction in any medium, provided the original author and source are credited. 
enhancing the protégés visibility within the organization, providing the protégé with coaching and protection $[8,20]$. The latter, psychosocial function includes an active role and a passive role. In the active role the mentor paves the way for the protégés social acceptance, confirmation and personal friendship. In the passive role, the mentor serves as a role model for the protégé in the organization $[8,10,20]$. The two mentoring functions serve different purposes. The career development function focuses on preparing the protégé for career advancement, while the psychosocial function serves to clarify the protégés sense of identity and develop a greater sense of competence [8]. Clutterbuck [21] also categorizes mentoring into two 'main' functions, but he has chosen to name them stretching and nurturing. Stretching concerns the provision of the protégé with counseling and guidance (being a guardian). Nurturing functions concern coaching and networking.

\section{Mentoring difficulties}

Difficulties that may arise in mentoring relationships are failure to establish a positive working alliance, problems of finding enough time and unclear definition of goals [22-24]. Mentoring relationships are intense, interpersonal complex and dynamic [23] and unpleasant incidents are a common and often neglected [23]. Mentoring relationships seems to suffer from four interpersonal difficulties, categorized as: difficulty, spoiling, deception and submissiveness [25].

Difficulty: Occurs when there are conflicts and disagreements between mentor and protégé [26], which are often correlated to differences in judgment, such as the expectations of the relationship [27].

Spoiling: Refers to a constructive relationship that stagnated because of real or perceived disloyalty or disappointment [26]. Although dysfunctional intent may not underlie destructive relations, it may simply be the case that the interactions between mentor and protégé become ineffective over time [25].

Deception: Closely related to sabotage, wherein both parties may engage in lies to damage the other's career or reputation or to set them up for failure [26]. This form of deception is malevolent with the intent of hurting or harming others, rather than preserving self-image [26].

Submissiveness: Bushardt et al. [26] note that mentor-protégé relationships imply imbalance in power, and that some protégés may offer submissive behavior in exchange for relational and organizational rewards mediated by more powerful mentors. Moreover, submissiveness may lead to over-dependence upon the mentor, which can create relational difficulties and lead to the termination of the mentoring relationship [25].

\section{Aim of the Study}

The purpose of the present study was to evaluate goals, activities and benefits of a mentoring program in order to provide an overall picture of three mentoring programs understanding how to improve future mentoring programs and developing the theoretical field of mentorship.

The following questions underpin the aims:

1. Which goals are common for the three mentoring programs and could be applied to compare the replies from the participants in order to identify any significant differences?

2. What are the participants' perceptions concerning the whole program, what was satisfying and what was less satisfying as regards career development, learning and psychological growth?
3. Which theoretical benefits might the protégés, the mentors and the organization have gained?

\section{Method}

\section{Participants}

The Company employed around 64,300 people and maintains operations in over 80 countries. In Sweden, there are 30 operations which employ about 4,500 people. The company is active within areas of pharmaceuticals, coatings and chemicals.

The study included 48 respondents, whereof 29 were mentors and 19 protégés. Some of the participants participated both as protégés and as mentors, and some mentors were mentors in more than one of the programs. The response rate was $83 \%$. Internal missing data occurred in $20 \%$ of the questions, and was at the most a total of eight persons. When the quantitative data had been collected, six persons (one mentor and one protégé from each mentoring program) were randomly selected to be interviewed.

\section{The mentoring programs}

Each of the three investigated mentoring programs had a set of defined goals. The two first programs " $t 1$ " and " $t 2$ " had identical goals, which were: "improve both protégés and mentors leadership competence, increase both protégés' and mentors' understanding of the importance of the working conditions in order to utilize others' competence, illuminate the conditions of career development, increase the opportunities for women to develop within the company, contribute to an increased number of female managers".

The goals of the third mentoring program, "t3", was: attract and retain high performers, foster inspiring leadership, develop options for succession, foster a collaborative environment by building trust and communication, promote diversity of thought and style, develop senior managers and give them an opportunity to benefit from the experiences and opinions of high-potential employees.

\section{Study design}

In the study, both quantitative and qualitative data were gathered. The quantitative data was used to evaluate the mentoring programs. The qualitative data was used to provide depth to the study. As the ambition was to illuminate and compare the mentors and the protégés perception of the mentoring programs goals and activities. Three goals were chosen to be evaluated, since only three of the goals of the two first mentoring programs ( $\mathrm{t} 1$ and $\mathrm{t} 2$ ) as readily adoptable on the last mentoring program ( $\mathrm{t} 3$ ). The activities in the mentoring programs evaluated were the discussions in the mentoring relationship, the seminars and the project work.

\section{Measures}

A questionnaire was used when gathering quantitative data. The questionnaire consisted of nine statements and seventeen questions. A second instrument was used when interviewing six randomly selected interviewees, one mentor and one protégé from each mentoring program. The questionnaire was divided into three parts. The first part was designed for mentors and protégés, and included two questions concerning the background variables, three statements regarding the goals, three questions concerning the activities, one question regarding the perception of the whole program and five open-ended questions. The second part was designed for the protégés only and the third for the mentors only. Both these parts consisted of three declarative sentences concerning benefits and three open-ended questions. The statements 
concerning the goals and the benefits were followed up by a question where the respondents were requested to list their previous replies. The purpose of this was to distinguish between the statements if the respondent had chosen same answering alternatives.

The semi structured interview was based on the same structure as the questionnaire. The interviewees were directed questions concerning what may have affected their answers in the questionnaire. For example, if an interviewee replied 'strongly agree' on one question the question was 'why' in form of what underlying factor or factors had contributed to that you feel that you strongly agree on the statement?

\section{Procedure}

The questionnaire was distributed to the participants by e-mail together with a cover letter. The participants where given a deadline of two weeks to reply. After the quantitative data was gathered, it was analyzed in SPSS.

The interviewees were selected randomly with the condition that one mentor and one protégé from each program should be interviewed. All of the interviews, except one, were performed 'face-to-face.' The final one was performed over the phone. In average, the interviews lasted about 40 minutes.

\section{Results}

\section{Evaluated goals}

In the present study, three of the goals of the mentoring programs were evaluated. Goal (A) was to 'Improve both protégés and mentors leadership competence', Goal (B) was to 'Increase both protégés' and mentors' understanding of the importance of the working conditions in order to utilize other peoples' competence, without consideration to gender, age, background or personality' and Goal (C) was to 'Illuminate the conditions of career development, and how these need to be in order to be able to recruit and retain future leaders.

Regarding Goal (A), about $5 \%$ of the respondents reported that they 'strongly agreed' that they had improved their leadership competence (Figure 1). $77 \%$ reported that they 'agreed'. During the interviews, the respondents were requested to recount what they believed was the main reason why they had improved their leadership competence. One of the interviewed mentors stated that the discussions with his protégé had generated reflections on how his own leadership could be improved. In addition, some of the interviewed protégés believed that the discussions in the mentoring relationship were one of the main factors for their improvement of their own leadership competence. Another factor was the exchanging of views with other protégés.

On the statement regarding Goal (B), 16\% replied that they 'strongly agreed' that they had increased their understanding for the importance of the working conditions (Figure 1). The interviews with the protégés showed that they believed that the discussions with other protégés, and the performed project work had contributed to their improved understanding for this goal. The interviewed mentors believed that discussing how the job could affect the family relation with their protégé, watching other organizations in more rapidly changing environments and own reading had provided them with a better understating for the importance of the working conditions in order to utilize other peoples' competence, without consideration to gender, age, background or personality.

Goal C achieved the highest mean, whereby $29 \%$ 'strongly agreed' that they had been enlightened on today's conditions of career

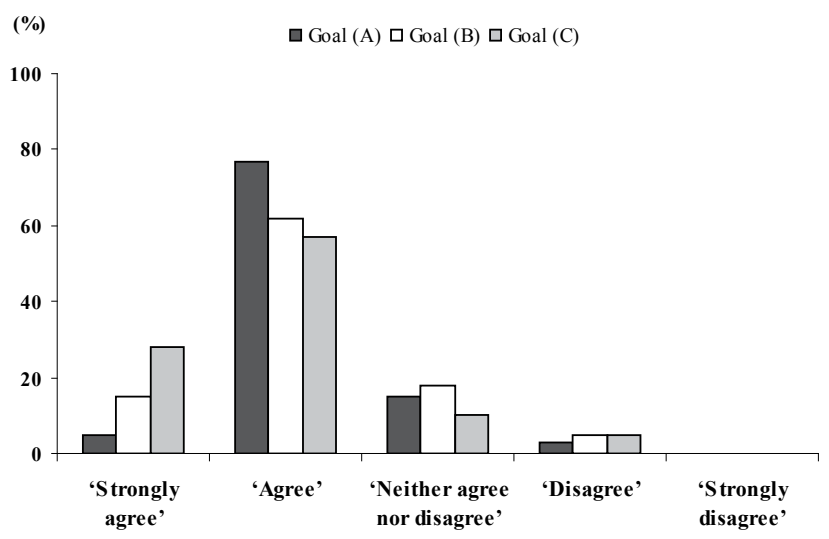

Figure 1: The results of the pertaining to the evaluated goals, expressed as a percentage of total responses.

development, and how these need to be changed in order to be able to recruit and retain future leaders (Figure 1). The protégés believed that they had obtained a better understanding of career development and how to deal with set-backs and fears. The mentors believed that they gained a deeper insight on how the working conditions need to be changed in order to be able to recruit and retain future leaders by listening to their protégés.

\section{The overall opinion concerning the mentoring programs}

The respondents that had participated in the first mentoring program ( $\mathrm{t} 1$ ) were the ones that were most positive towards the whole mentoring program. The overall mean of this year variable was 4.75 , outlined in (Figure 2). Moreover, the study showed that participants from the second mentoring program ( $\mathrm{t} 2$ ) seemed to be the ones that perceived the mentoring program most negatively (Figure 2).

In the end of the questioner space was left for general comments. A few of the respondents had something to add, and in Table 1 some of these comments are given.

\section{Evaluated activities}

The activities in the mentoring programs evaluated in this study are: a) the dialogues ('interactions') in the mentoring relationship, b) the seminars and c) the project work. a) $50 \%$ of the respondents replied that they found the dialogues in the mentoring relationship 'very good'. 44\% replied that the dialogues were 'good' and 5\% replied that they were 'neither good nor bad'. None had, however, found the dialogues in the mentoring relationship 'poor' or 'futile'. b) Concerning the seminars, 33\% replied that they found the seminars 'very good. $3 \%$ classified them as poor. c) In the last mentoring program (t3) the project work was an optional part of the program. Hence, $11 \%$ of the replies are classified as 'not applicable'. $32 \%$ of the respondents who had participated in the project work found it 'very good'. The frequencies of the replies are shown in Figure 3.

According to the responses from both mentors and protégés, the most negative experience from the mentoring relationship was finding enough time and to create a schedule. In some cases the travel distance was perceived to influence the relationship negatively. The most positive experience the mentors have had from the mentoring relationship was the dialogues, which enabled sharing of knowledge and views that generated thoughts and reflections. Most of the protégés shared the mentors' view that the dialogues were the best part of the mentoring relationship. They described the dialogues as open discussions in 


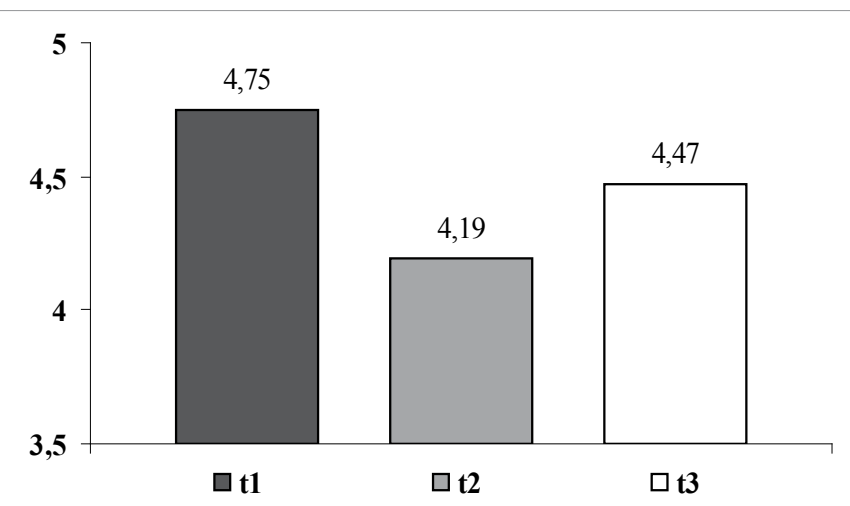

Note: $(1=$ very poor; $5=$ very good $)$

Figure 2: The overall opinion concerning the mentoring programs. The different programs are compared. The respondents who participated in the first mentoring program where also the ones being most positive.

\section{Last Comments}

"This period was the first period without a project. Personally, I think a project needs to be included but keep the ambition on a pretty low level."

"It is good to have a mentoring program, even though it could create time pressure in your mentoring relationship, but otherwise the program is just a complement to what really makes it worth being a mentor, the relationship."

"So far, the long term gain for me has been the contact with the protégé group. It is a very good network."

"...It was also interesting to see how differently we work in the different BU's and I got great input on how to make the work in my own organization more structured.' "I had a mentor who was very similar to me. This encouraged me in my own role and it was nice to hear someone with the same opinion as myself concerning leadership (my own boss has a very different opinion on what leadership means)."

"If I ever get a mentor again I would like to have someone quite different from myself in order to understand how a typical male manager in his 50:s thinks and hopefully make him see some things from a different point of view."

Table 1: Other comment regarding the mentoring programs.

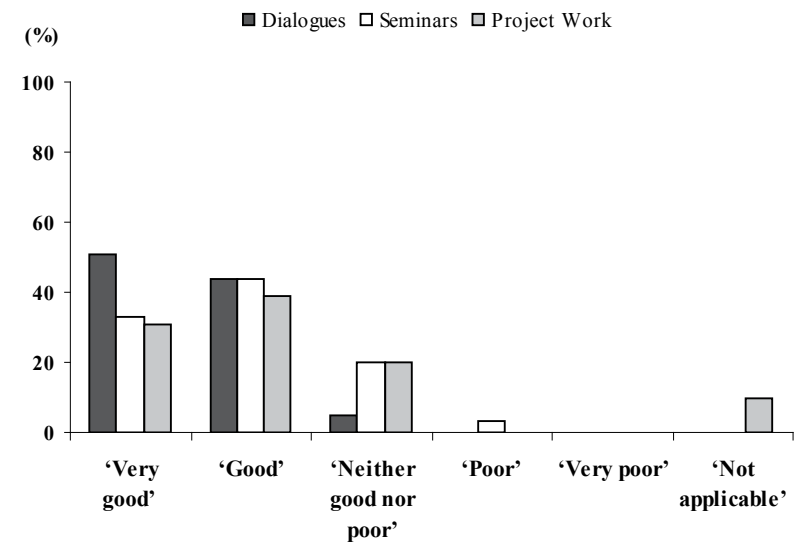

Figure 3: The frequencies of the responses pertaining to the activities in the mentoring programs, expressed as a percentage of total responses.

which the mentors shared their experience, knowledge, and provided them with good advice. A majority of the protégés claimed that the psychological growth had been vastly improved due to the support given by their mentors and that their capability of dealing with stress and set-backs was improved.

The interviewees were asked: 'What subjects dominated the dialogues in the mentoring relationship, and what has been the source of inspiration for these dialogues?' The result shows that common subjects in the dialogue between mentors and protégés were: a) the job of the mentor as well as the protégé, b) the protégés' role in the organization and c) the protégés new job or position within the organization and future opportunities of career development. The protégés' job was interpreted as the most common source of inspiration for the dialogues in the mentoring relationship.

In Table 2 positive and negative comments from the interviews concerning the seminars and the activities in the programs are presented.

\section{Evaluated benefits}

In the theoretical framework, the possible benefits of mentoring were presented. In the empirical study three benefits for mentors and protégés were evaluated. The benefits were evaluated from one statement for each benefit.

\section{Protégés' benefits}

The evaluated benefits for the protégés were: Benefit (A) 'A greater comprehension of the organizations context', Benefit (B) 'A greater awareness of own strengths and weaknesses' and Benefit (C) 'A greater comprehension of a manager's role in the organization'.

In Figure 4 it is shown that $20 \%$ of the protégés responded that they 'Strongly agree' that they have developed a greater understanding of the organizations' context. $27 \%$ have answered that they 'Strongly agree' that they had gained both from an increased awareness of own strengths and weaknesses and a greater comprehension of a mangers' role in the organization, while $7 \%$ replied that they 'neither agree nor disagree' on that they had developed a greater understanding for a manger's role

\begin{tabular}{|l|l|l|}
\hline S. No & \multicolumn{1}{|c|}{ Positive comments (+) } & \multicolumn{1}{|c|}{ Negative comments (-) } \\
\hline 1 & $\begin{array}{l}\text { Some of the seminar had good } \\
\text { themes that opened for discussions }\end{array}$ & $\begin{array}{l}\text { Increase the quality of the seminars } \\
\text { or remove them from the program }\end{array}$ \\
\hline 2 & $\begin{array}{l}\text { All seminars where good. Great with } \\
\text { 'know-your-self' seminars }\end{array}$ & $\begin{array}{l}\text { The seminars were long-winded and } \\
\text { of poor quality }\end{array}$ \\
\hline 3 & $\begin{array}{l}\text { The activities in the program gave } \\
\text { us the opportunity to meet other } \\
\text { protégés and learn from each other's } \\
\text { experiences }\end{array}$ & $\begin{array}{l}\text { Can hardly remember the activities, } \\
\text { perhaps, because they were not } \\
\text { much to remember. Believe the } \\
\text { relation to the protégé was more } \\
\text { instructive." }\end{array}$ \\
\hline
\end{tabular}

Table 2: Positive and negative comments from the interviewees concerning the seminars and the activities.

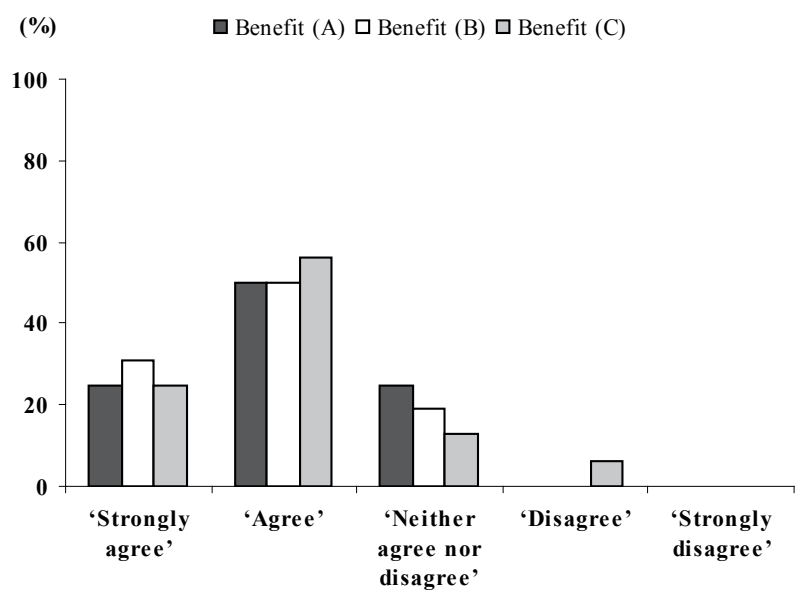

Figure 4: Percentage of total responses of the protégés' responses expressed for each of the benefits $A, B$, and $C$. 
in the organization. None of the protégés had, however, answered that they 'strongly disagree' on any of the statements. The interviews with the protégés showed that one of the protégés had the opportunity to follow the mentor while he was leading organizational restructuring work, which contributed to the protégés improved understanding of the organizational context. All of the protégés who were interviewed stated that they had become more aware of their own strengths and weaknesses after having been participated in the mentoring program. None of the protégés stated, however, that they had obtained this benefit due to the mentoring relationship. It was shown that they believed that comparing themselves with other protégés was what had made them more aware of their own strengths and weaknesses. The protégés interviewed were requested to indicate if they believed that participating in the mentoring program had made them more aware of a managers' role in the organization. All of the protégés agreed that they had gained a better comprehension of the managerial role in the organization, mostly due to the opportunity to obtain an insight of a manager's role through their relationship with their mentor.

\section{Mentors' benefits}

As for the protégés three benefits for the mentors were evaluated. The evaluated benefits were: Benefit (A) 'Better understanding for the younger generations way of thinking', Benefit (B) 'New skills' and Benefit (C) 'Increased level of job satisfaction'. As can be observed in Figure 5, the highest percentage on the reply alterative 'strongly agree' was dedicated to the benefit of a greater understanding for the younger generations' way of thinking. $4 \%$ of the mentors replied that they 'disagreed' that being a mentor increased their job satisfaction. It was shown from the interview with one of the mentors that the reason he did not feel any job satisfaction was because the length of the relationship was short and there were not enough time to be able to efficiently help anyone and see the results of it. The two other interviewed mentors replied that the mentoring program had effected their job satisfaction positively, mostly because of the variation provided from their ordinary jobs.

\section{Comparison of goals}

After have been analyzing the results and compared the variables of mentors and protégés, it was shown a significant result between the two respondent groups' concerning one of the evaluated goals (Table 3).

The mentors were more negative in their replies than the protégés concerning Goal A $(\mathrm{p}<0.05)$, which can be discerned by comparing the great mean of the respondents groups in (Table 4). There was no significant difference found between the respondent groups' replies concerning Goal B and Goal C.

Results concerning the activities showed a statistical significant difference between mentors and protégés as regards seminars $(\mathrm{p}<0.05)$ (Table 5).

Differences between the mentors from the different mentoring programs were analyzed. However, no significant results between the mentors' replies from the different mentoring programs were noted. The replies of the protégés from the different mentoring programs were also analyzed (Table 6). Significant differences between the protégés replies from the different mentoring programs were identified as regards dialogues. A post hoc test (Bonferroni) showed a significant difference between the protégés of the mentoring program at $t 1$ and the protégés of the mentoring program at $\mathrm{t} 3(\mathrm{p}<0.05)$.

\section{Discussion}

\begin{tabular}{|c|c|c|c|}
\hline S.No & In a Mentor & In a Protégé \\
\hline & & Listening 10 & Openness 8 \\
\hline & Mentors & Openness 2 & Listening 2 \\
\hline & & Other 8 & Other 9 \\
\hline & & Openness 3 & Total $\mathbf{( n )} \mathbf{1 9}$ \\
\hline & & Interested 2 & Openness 3 \\
\hline & Protégés & Communication 2 \\
\hline & & Leadership 2 & Interest 2 \\
\hline & & Other 6 & Other 8 \\
\hline & & Total $\mathbf{1 5}$ & Total $\mathbf{( n )} \mathbf{1 6}$ \\
\hline
\end{tabular}

Note: $n=$ number of respondents

Table 3: The most important skills in a mentor and a protégé.

In the analysis of the results three significant differences were found. The first difference concerned the replies on Goal A (i.e., improve both protégés and mentors leadership competence). The main reason for this statistical significant difference could be that at the time of the study, the mentors were more negative in their replies than the protégés concerning this goal. There may be several explanations for this. One could be that most of the mentors were too experienced and did not feel that the mentoring program or the mentoring relationship had developed their own leadership competence. On the other hand, a majority (75\%) of the mentors had replied that they 'strongly agreed' or 'agreed' that they had developed a better understanding for the younger generations' way of thinking. This increased understanding may contribute to an improved leadership competence as the understanding for the junior employees' way of thinking could facilitate the work as a manger. One mentor replied that communication worked out better after the mentoring relationship. Communication is essential in good leadership [27], and practicing both verbal and non-verbal communication in a mentoring relationship might thus improve the leadership of the mentors. The results of the study also indicated that the respondents had a very positive view towards the dialogues in the mentoring relationship. This applies to the mentors as well as the protégés.

The second statistically significant difference between mentors and protégés perceptions occurred with regard to the seminars. Here too, the mentors were more negative than the protégés.

The third significant difference was found between the protégés responses from the different mentoring programs, which showed that a statistically significant difference was identified between the protégés of the mentoring program at $\mathrm{t} 1$ and $\mathrm{t} 3$. This development could, however, be interpreted as positive, where the mentors at the company have become better in providing insightful discussions. It concerns the overall perception of the mentoring program decreased over the years, as well for the protégés as the mentors. Are the expectations higher today than before or is the quality poorer? Expectations and perceptions of mentors and protégés are rarely defined or communicated [26].

Too high expectations may exist if there is a lack of pre-information regarding the purpose and the goals of the mentoring program. It was, for instance, shown in the study that many of the protégés did not know why and how they had been selected. Human Resource professionals should ensure that both parties fully understand their roles in the mentoring program, what they will get out of the mentoring and how it is supported by the Human Resource department [28].

When mentors and protégés are formally assigned they may be less motivated and less personally involved in the mentoring relationship. 
Citation: Ricciardi MR, Archer T (2016) Designed Mentorship, Career Development, Learning and Psychological Growth across Generations: A Study of a Mentoring Program in an International Industrial Company. Clin Exp Psychol 2: 144. doi: 10.4172/2471-2701.1000144

Page 6 of 8

\begin{tabular}{|c|c|c|c|c|c|c|c|c|}
\hline & \multicolumn{3}{|c|}{ Mentors } & \multicolumn{3}{c|}{ Proteges } & \multicolumn{2}{c|}{ t-value } \\
\cline { 2 - 8 } & N & Mean & SD & N & Mean & SD & \\
\hline Goal A & 23 & 3.70 & 0.63 & 16 & 4.06 & 0.25 & -2.51 \\
\hline Goal B & 23 & 3.96 & 0.82 & 16 & 3.75 & 0.58 & 0.864 \\
\hline Goal C & 23 & 4.04 & 0.77 & 16 & 4.13 & 0.81 & -0.32 \\
\hline
\end{tabular}

Note: 1) Goal A 'Improve both protégés and mentors leadership competence'; Goal B 'Increased both protégés and mentors understanding for the importance of the working conditions in order to utilize other peoples' competence, without consideration to gender, age, background or personality'; Goal C 'Illuminate the conditions of career development, and how these need to be changed in order to be able to recruit and retain future leaders'

Table 4: Independent sample t-tests of the evaluated goals.

\begin{tabular}{|c|c|c|c|c|c|c|c|c|}
\hline & \multicolumn{3}{|c|}{ Mentors } & \multicolumn{3}{c|}{ Proteges } & Sig. \\
\cline { 2 - 9 } & $\mathbf{N}$ & Mean & SD & N & Mean & SD & \\
\hline Dialogues & 23 & 4.39 & 0.66 & 16 & 4.56 & 0.51 & -0.91 \\
\hline Seminars & 23 & 3.78 & 0.74 & 16 & 4.50 & 0.73 & -3.00 \\
\hline Projects & 21 & 4.00 & 0.77 & 14 & 4.29 & 0.73 & -1.09 & 37 \\
\hline
\end{tabular}

Note: 1) Dialogues=In the mentioning relationship 2) Mean: strongly agree=5; strongly disagree=1. 2) Mean: strongly agree=5; strongly disagree=1

Table 5: Independent sample t-test of the evaluated activities.

\begin{tabular}{|c|c|c|c|c|c|c|c|c|c|}
\hline $\begin{array}{l}\text { Goals and } \\
\text { Activities }\end{array}$ & Protégés at time $1(\mathrm{t} 1)$ & SD & Protégés at time 2 (t2) & SD & Protégés at time $3(\mathrm{t} 3)$ & SD & df1df2 & F-value & Sig. \\
\hline Goal (A) & 4.33 & 0.58 & 4.00 & 0.00 & 4.00 & 0.00 & 213 & 2.64 & 0.11 \\
\hline Goal (B) & 4.33 & 0.58 & 3.67 & 0.52 & 3.57 & 0.53 & 213 & 2.25 & 0.14 \\
\hline Goal (C) & 4.67 & 0.58 & 3.83 & 0.41 & 4.14 & 1.07 & 213 & 1.08 & 0.37 \\
\hline Dialogues & 4.00 & 0.00 & 4.50 & 0.55 & 4.86 & 0.38 & 213 & 4.36 & $<0.05$ \\
\hline Seminars & 5.00 & 0.00 & 4.33 & 0.82 & 4.43 & 0.79 & 213 & 0.88 & 0.44 \\
\hline Project Work & 4.33 & 0.58 & 4.67 & 0.52 & 3.80 & 0.84 & 211 & 2.36 & 0.14 \\
\hline
\end{tabular}

Table 6: One-way ANOVA test of the protégés replies with mean values and standard deviations (SD).

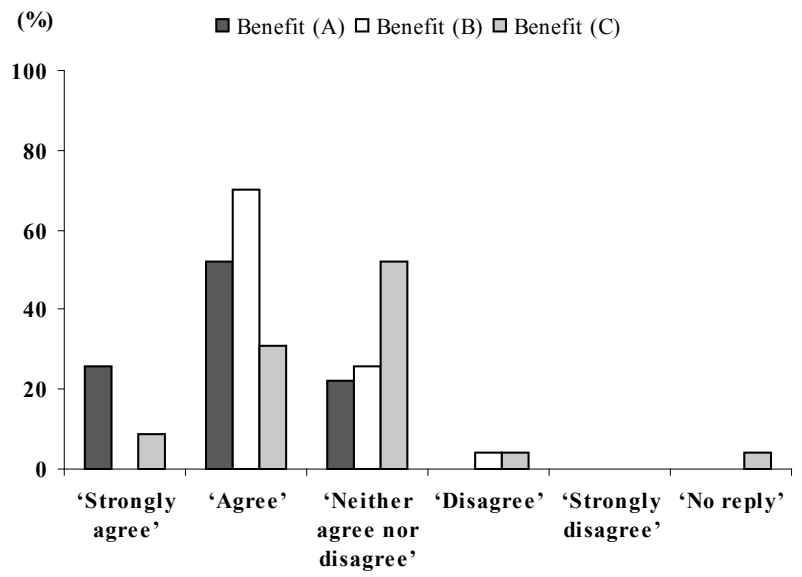

Figure 5: Percentage of total responses of the mentors responses expressed for each of the benefits $A, B$, and $C$.

Some mentors may also lack the necessary communication and coaching skills, and may be less likely to actively intervene on the protégés behalf because the relationship is public and monitored by program coordinators [15]. Thus, it is of great importance that the mentoring programs inspire the mentors, who in turn inspire the protégés.

\section{Inspiring the mentors}

Mentoring programs could help the protégés towards learning and self-actualization in their professional development and possibly promote or assign them to future managerial posts [18] thereby providing further comments on improving self-trust and psychological stamina that seemed to be a consequence of the relationship. What about the mentors that already posses a managerial position and consider themselves as successful leaders? Some mentors may find satisfaction in helping and seeing their protégé succeed, and from the study it was shown that the formal mentoring relationship was too short for the mentor to both be able to help a protégé and then see the result of it. Thus, mentors may need to find other sources of satisfaction. In the long-term, the mentoring program may obtain positive gains if the mentors could achieve some level of self-actualization in their role as mentors. Nevertheless the question remains, how may the mentoring program inspire the mentors towards a self-actualization in their role as a mentor? One ought not to exclude the fact that mentors may envy of their protégés, if they are not given the chance to fulfill themselves.

One suggestion is to implement a mentoring hierarchy, based on Maslow's [29] self-actualization, where a mentoring hierarchy could

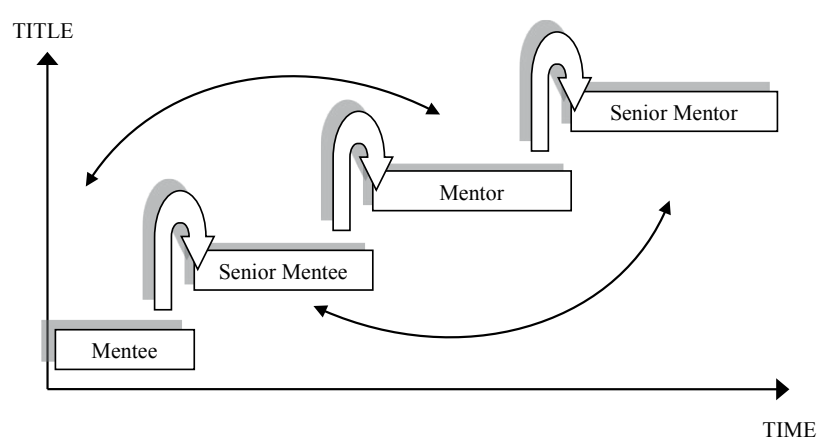

Figure 6: A tentative model presenting a "mentoring" hierarchy as a function of managerial status and elapsed time. 
Citation: Ricciardi MR, Archer T (2016) Designed Mentorship, Career Development, Learning and Psychological Growth across Generations: A Study of a Mentoring Program in an International Industrial Company. Clin Exp Psychol 2: 144. doi: 10.4172/2471-2701.1000144

Page 7 of 8

inspire both protégés and mentors to climb in the mentoring hierarchy (Figure 6).

At this level the help could be more on a psycho-social level where new the recruited could be integrated into the organization and guided into its culture and values. When this first step has been carried out the protégé will have the opportunity to become a senior protégé. In this phase the protégé will be assigned a senior mentor who can help the protégé with work and career related issues. The senior protégé could become a mentor and provide mentoring to new recruit. The suggestion is that in the final stage of the mentoring hierarchy the mentors with several years of mentoring experience may achieve the title of a senior mentor.

At the initiation of the mentoring hierarchy the protégés learn the basic rules of mentoring as newly recruited individuals and are provided mentoring help from mentors. When the mentor has been in the organization for a couple of years the protégé may be promoted to a senior protégé and thus obtain mentoring help from senior mentors. The notion is that the senior protégé may obtain more work and career developmental support from the senior mentor who is selected from, for example, the mentor data base at the company by the protégé. The mentoring relationship is initiated after it has been approved by the Human Resource department and a mentoring plan has been developed. The mentoring relationship could still be formal and evaluated on termination, whereby statistical data gathered may be analyzed to indicate the success of the mentoring relationship. Implementing a mentoring hierarchy is designed to provide the mentor with the opportunity to strive for self-actualization in the role as a mentor. For instance, the mentor could find new techniques of how to provide mentoring help, how to inspire the protégé to ask questions. For example, in the establishing rapport phase, the mentor and the protégé are supposed to get to know one another. In the present study, it was shown that the mentors found that the most important skill in a mentor and a protégé was to listen and to be open, which also are the required skills in the establishing rapport phase.

\section{Structuring the mentoring relationship}

Formal mentoring relationships are generally shorter in duration than natural mentoring relationships. It was shown in the study that several mentors and protégés had difficulties in finding time for the mentoring process. Assigning time is also a common issue in mentoring [22-24]. Thus, structuring mentoring relationships may have to be considered in order meet with the expectations and make the procedure as time-efficient as possible.

In the theoretical framework, two different theories concerning the steps of natural mentoring relationships were presented. In the first step, establishing rapport, the protége and the mentor ought to discuss and define the nature of their relationship and their respective roles. In a natural mentoring relationship a mentor remains essentially supportive. In a formal mentoring relationship the mentor and protégé may have to focus more upon the mentoring by identifying the protégés' needs and then defining the role of the mentor. For example, the protégé needs help with a new working assignment. The protégé and the mentor may then together outline which function(s) should predominate the mentoring facility. Nevertheless, some protégés may not want that kind of direct mentoring help. By discussing the role of the mentor in the 'establishing-rapport' phase the protégé has the opportunity to inform the mentor about what kind of mentoring help he/she prefers. A clear understanding of what help the protégé wants and how it should be delivered could result in a successful establishing rapport phase and at the same time the mentor and the protégé will be able to familiarize with one another, which is the task at this phase. When the protégé and the mentor have a clearer understanding of what kind of mentoring the protégé prefers, a 'Mentor/Protégé Contract' ought to be applied in the second step, the 'direction-setting' phase. However, the template used in the mentoring program at the company ought to focus more on the goals by distinguishing between the commitments and the goals in the contract.

\section{Conclusion}

The protégés in the mentoring program have demonstrated the capacity to acquire a greater comprehension of the organizational context, which includes the understanding of the organizational culture, structure, business process and allocation of the resources and the power within the organization, under mentorship. The protégés have shown also a positive attitude indicating that the mentoring program contributed to an increased awareness of their own strengths and weaknesses, as well as a more prominent awareness of the managers' role in the organization. The mentors expressed an improved understanding for the younger generations' way of thinking and had also developed new skills. The role of mentor had not increased the level of job satisfaction for the majority of the mentors.

The significant differences noted between mentors and protégés may indicate that the mentoring programs at the company suited the protégés better than the mentors themselves. From the results of this empirical study it can, however, be concluded that the benefits accruing to the organization pertains to the situation that potential future leaders of the organization have obtained a clearer picture of what kind of commitments are to be made in order to become a manager at the company. This increased understanding of a managers' role in the organization will benefit also the organization with the void between current leaders and future leaders if not totally erased at least lesser in extent. Nevertheless, it cannot be determined whether or not the benefits are in fact the result of mentoring since an appropriate control group is missing. The current study determines the degree to which one activity (protégé development) may benefit more than another (mentor development).

Finally, it was confirmed from the present study that the mentors and protégés involved experienced significantly different parts of the mentoring programs. Differences in perception, however, will always exist but in order to reverse any negative trend these differences ought to be attended to. A positive trend was noted as the protégés were more positive on the dialogue responses in the mentoring relationships over time.

\section{References}

1. Rapp-Ricciardi M, Schaller J, Garcia D, Archer T (2015) Coaching leadership training in high-tech settings: An analysis of a coaching leadership program in the Swedish telecom industry. IJEBCM.

2. Rapp-Ricciardi $M$, Åkerman J, Eerikäinen $P$, Ambjörnsson A, Andersson AC (2014) Understanding Group and Leader (UGL) trainers' personality characteristics and affective profiles. Front Psychol 10: 1191.

3. Caruso RE (1992) Mentoring and the business environment. Dartmounth Publishing, Aldershot.

4. Crosby FJ, Ely RJ, Murrell AJ (1999) Mentoring dilemmas: Developing relationships within multicultural organizations. Lawrence Erlbaum Associates, New Jersey.

5. Eby LT, Allen TD, Evans SC, Ng T, DuBois D (2014) Does mentoring matter? A multidisciplinary meta-analysis comparing mentored and non-mentored individuals. J Vocat Behav 72: 254-267.

6. Megginson D, Clutterbuck D, Garvey B, Garrett-Harris R (2005) Mentoring in 
Citation: Ricciardi MR, Archer T (2016) Designed Mentorship, Career Development, Learning and Psychological Growth across Generations: A Study of a Mentoring Program in an International Industrial Company. Clin Exp Psychol 2: 144. doi: 10.4172/2471-2701.1000144

Page 8 of 8

action - a practical guide ( $2^{\text {nd }}$ edn.). Kogan Page, London and Philadelphia.

7. Megginson D, Clutterbuck D (2006) Creating a coaching culture. Industrial and Commercial Training 38: 232-237.

8. Chao GT, Waltz PM, Gardner PD (1992) Formal and informal mentorships: A comparisons on mentoring functions and contrast with nonmentored counterparts. Pers Psychol 45: 619-636.

9. Bell CR (2002) Managers as mentors: Building partnership for learning (2nd edition). Berrett-Koehler, San Francisco.

10. Campbell-Whatley GD (2001) Mentoring students with mild disabilities: The "nuts and bolts" of program development. Interv Sch Clin 36: 211-216.

11. http://80-web18.epnet.com.proxy.lib.chalmers.se

12. Hamilton R (1993) Mentoring: A practical guide to the skills of mentoring. The industrial society, London.

13. Murray M, Owen MA (1991) Beyond the myths and magic of mentoring: How to facilitate an effective mentoring program. Jossey-Bass, San Francisco.

14. Ragins BR, Cotton JL (1999) Mentor functions and outcomes: A comparison of men and women in formal and informal mentoring relationships. J Appl Psychol 84: $529-550$

15. Alleman E, Clarke DL (2000) Accountability: Measuring mentoring and its bottom line impact. Review of Business 21: 62-67.

16. Viator RE (1999) An analysis of formal mentoring programs and perceived barriers to obtaining a mentor at large public accounting firms. Accounting Horizons 13: 37-53.

17. Morzinski JA, Fisher JC (1996) An evaluation of formal mentoring and a model for their improvement. Eval Pract 17: 43-56.
18. O'Reilly D (2001) The mentoring of employees: Is your organisation taking advantage of this professional development tool? The Ohio CPA Journal 60: 51-54.

19. Lewis G (1996) The mentoring manager: Strategies for fostering talent and spreading knowledge. Pittman Publishing, London.

20. Scandura TA, Viator RE (1994) Mentoring in public accounting firms: An analysis of mentor-protégé relationships, mentorship functions, and protégé turnover intentions. Accounting, Organizations and Society 19: 717-734.

21. Clutterbuck D (2001) Everyone needs a mentor: Fostering talent at work. CIPD Enterprises, London.

22. Eby LT, McManus SE, Simon SA, Russell JEA (2000) The protégé's perspective regarding negative mentoring experiences: The development of taxonomy. J Vocat Behav 57: 1-21.

23. Stone $F$ (1999) Coaching, counseling and mentoring: How to choose and use the right techniques to boost employee performance. AMACOM, New York.

24. Eby LT, McManus SE (2004) The protégé's role in negative mentoring experiences. J Vocat Behav 65: 255-275.

25. Scandura TA (1998) Dysfunctional mentoring relationships and outcomes. Manag 24: 449-467.

26. Young AM, Perrewé PL (2000) The exchange relationship between mentors and protégés: The development of a framework. Hum Resour Manage 10: 177209.

27. Lang PGA (1992) First level management: An active-learning approach. Pittman Publishing, London.

28. Pettit L (2004) Mentoring will motivate. Personnel Today 4: 20-21.

29. Maslow A (1954) Motivation and personality. Harper, New York. 